Voix et Images

volXetimages

\title{
Index du volume XXVI
}

Volume 27, numéro 1 (79), automne 2001

Fernand Dumont

URI : https://id.erudit.org/iderudit/201598ar

DOI : https://doi.org/10.7202/201598ar

Aller au sommaire du numéro

Éditeur(s)

Université du Québec à Montréal

ISSN

0318-9201 (imprimé)

1705-933X (numérique)

Découvrir la revue

Citer ce document

(2001). Index du volume XXVI. Voix et Images, 27(1), 178-179.

https://doi.org/10.7202/201598ar d'utilisation que vous pouvez consulter en ligne.

https://apropos.erudit.org/fr/usagers/politique-dutilisation/ 


\section{Index du volume XXVI}

ANDRÈS, Bernard, "D'une mère partie à la patrie canadienne : archéologie du patriote au XVIII ${ }^{e}$ siècle ", 3, p. 474-497.

BARIL, Geneviève, "L'immonde comme dessein, mobile et délit d'écriture", 1, p. 40-59.

BERND, Zila et Maria Bernadette PORTO, "Vingt ans d'études québécoises au Brésil ", 1, p. 194-198.

BERNIER, Marc André, "Patriotes et orateurs: de la classe de rhétorique à l'invention d'une parole rebellen, 3, p. 498-515.

BIRON, Michel, "Devant quelques photos de famille", 1, p. 177-182; "Le plaisir d'être second ", 2, p. 401-405; "Une poète, un journaliste, un romancier ", 3, p. 625-630.

BONIN, Linda, " Ce qui, d'une écriture, n'est pas à lire" ", 2, p. 288-301.

BROCHU, André, "La poésie et l'expérience de soi ", 1, p. 183-186; "Poèmes en rouge ", 3, p. 631-635.

CARDINAL, Jacques, "Exorciser l'immonde. Parole et sacré dans Sainte Carmen de la Main de Michel Tremblay", 1, p. 18-39.

CHASSAY, Jean-François, "Avant-propos", 1, p. 5-6; "Avant-propos", 2, p. 221-222; "Avant-propos", 3, p. 445-447.

CLICHE, Anne Élaine, "L'immonde. Ceci n'est pas un thème" (Présentation), 1, p. 9-15; "Fêtes pour la fin des temps. Sur les tableaux de Dominic Besner", 1, p. 16-17.

COUILLARD, Marie et Patrick IMBERT, "Parler au nom du peuple au Xix ${ }^{e}$ siècle au Canada français : arguments et décontextualisation ", 1, p. 109-127.

DÉCARIE, David, “Le relais des survenants chez Germaine Guèvremont ", 2, p. 359-383.

DESAUTELS, Denise, "Pendant la mort " (extraits), 2, p. 241-246.

DION, Robert, “Expériences de l'altérité ", 2, p. 415-422.

DUMONT, François, "Politiques littéraires", 1, p. 169-173; "Médiations critiques", 2 , p. 397-401; "Refaire l'histoire „, 3, p. 619-622.

DUPRÉ, Louise, "Présentation", 2, p. 225-226; "D'abord l'intime. Entretien avec Denise Desautels", 2, p. 227-240; "Déplier le temps: mémoire et temporalité dans $L a$ promeneuse et l'oiseau et Ce fauve, le Bonheur de Denise Desautels ", 2, p. 302316.

GERVAIS, Bertrand, "L'art de se brûler les doigts. L'imaginaire de la fin dans La petite fille qui aimait trop les allumettes de Gaétan Soucy", 2, p. 384-393.

HAREL, Simon, "L'immonde "ordinaire" des secrets de famille dans l'œuvre de Julien Bigras ", 1, p. 60-73.

HUDON, Jean-Paul, "Henri-Raymond Casgrain, Gédéon Ouimet et les livres donnés en prix dans les écoles de 1876 à 1886 n, 3, p. 596-616. 
KIRSCH, Fritz Peter, "La littérature québécoise dans le cadre des études francophones en Autriche ", 2, p. 422-426.

LANDRY, Gabriel, "Habiter l'image ", 2, p. 406-411 ; "D'alarme et d'amour ", 3, p. 636641.

LEDUC, Mario, aLe bonheur autrement. L'héritage décrié de Robinson Crusoé dans Les grandes marées de Jacques Poulin", 3, p. 569-584.

LEMIRE, Maurice, "Félicité Angers sous l'éclairage de sa correspondance", 1, p. 128144.

MAJOR, Robert, "Le patriote pathétique (Le patriote de la Révolution tranquille)", 3, p. 539-555.

MALENFANT, Paul Chanel, "Écrire comme mourir: tombeau des mots ", 2, p. 247-263.

MARCOTTE, Sophie, " Je n'écris que pour écrire...": les lettres de Jacques Ferron à ses sœurs ", 3, p. 585-595.

NARDOUT-LAFARGE, Élisabeth, "Ducharme, du sale et du propre ", 1, p. 74-94.

OUELLET, Pierre, "L'une comme l'autre : compassion et coénonciation dans Cimetières : la rage muette, 2 , p. 264-274.

PAQUIN, Julie, "Voyage au cœur de l'immonde ou La fouille exploratrice de Claude Gauvreau ", 1, p. 95-106.

PARÉ, François, "La figure de la répétition dans l'œuvre de Denise Desautels ", 2, p. 275-287.

PATRY, Richard, "Le gentilhomme allemand et les voleurs d'âme: "Loutiquenne" et les "(de) Quéclin" dans l'univers ferronienn, 1, p. 145-165.

RANDALL, Marilyn, "Plus patriote que ça... Fictions du patriote $1847-1981$ ", 3, p. 516538.

RANDALL, Marilyn et Daniel VAILLANCOURT, "Entretien avec Micheline Lachance ", 3, p. $556-565$.

ROBERT, Lucie, "Le corps déréglé ", 1, p. 187-193; "L'art du conteur ", 3, p. 641-648.

ROY, Véronique, "La réception critique de Charles Guérin de Pierre-Joseph-Olivier Chauveau au $x_{x}{ }^{e}$ siècle. De l'émergence d'une littérature nationale», 2, p. 339-358.

ST-AMAND, Patrick, "Bibliographie de Denise Desautels", 2, p. 317-335.

SAINT-MARTIN, Lori, “Deux lieux communs revisités ", 2, p. 411-414.

SAVOIE, Chantal, "La petite vie ou les entrailles d'un peuple», 3, p. 623-625.

VAILLANCOURT, Daniel, "Les têtes à Patriote: une figure retorse au XIx ${ }^{\mathrm{e}}$ siècle", 3, p. $456-473$.

VAILLANCOURT, Daniel et Marilyn RANDALL, "Généalogies de la figure du Patriote 1837-1838* (Présentation), 3, p. 451-455.

VANDENDORPE, Christian, "Excursions dans les univers de la science-fiction ", 1, p. 173-177. 